\title{
A SOCIAL WORK PRACTICE PERSPECTIVE ON MIGRATION
}

\section{Wim Roestenburg}

\section{INTRODUCTION}

"Migration is one of the defining features of our contemporary world, [yet] it remains one of the most misunderstood issues of our time. Gaone Dixon" (Parker, 2012)

From time to time reports about xenophobic attacks on foreigners make news headlines in South Africa. As recently as September 2012 the Mail and Guardian reported on the distribution of letters to foreigners living in Mayfair, Johannesburg, threatening them with death because they are foreign (Parker, 2012). The phenomenon of migration, refugees and citizens fleeing their country of origin to settle in another country is an internationally recognised phenomenon and one that is relevant to social work practice. The social work profession strives to improve the quality of life of all as well as promoting social justice, inclusive of immigrants and refugees, without getting involved in the political or ideological struggle associated with the country's foreign policy (Hepworth, Rooney, Rooney \& Strom-Gottfried, 2013:4). Social workers intervene in migrant-related issues during the course of their day-to-day practice.

Post-apartheid South Africa is regarded as popular migration destination, mainly by citizens of neighbouring countries such as Zimbabwe. Although the exact figures are unknown, it is estimated that one in every five citizens may be a migrant (Valji, 2003). Polzer, in "Population movements in and to South Africa" (n.d.) indicates the figure of unprocessed asylum claims for 2010 to be in the region of 180 000, while (Anon., 2012) indicates some 219368 unprocessed and pending asylum claims for the country. This influx of foreign citizens creates pressure on economic and physical infrastructure, support systems and the capacity of society to accommodate immigrants. Foreigners are often perceived with scepticism, a result of intolerance frequently based on race and social exclusion (Abrams, Hogg \& Marques, 2005). As a result of exclusionist perceptions that foreigners compete with locals for employment and scarce resources, they are blamed for every conceivable social ill and therefore marginalised and regarded as not included in the local in-group (Esses, Dovidio, Semenya \& Jackson, 2005:318). These perceptions may have contributed to the occurrence of several incidents of xenophobic attacks on foreigners in various parts of South Africa in 2008-2009, resulting in the deaths of 62 foreigners (Nord \& Assubuji, 2010:1). There is evidence that a growing sense of nationalism among locals can be regarded as the main contributing factor to an attitude that treats everybody who enters the country's borders without documentation as unwanted (Posel, 2003; Valji, 2003). Esses et al. (2005:320) regard nationalism as different from patriotism in that "otherness" in nationalism contrasts more strongly with one's own group identity and correlates significantly with disparagement of immigrants. They describe nationalism as a "belief in the superiority of one's own nation compared to others", thereby explaining the basis for exclusionist behaviour that contributes to the vulnerability of foreigners. 
In 2008, in response to foreigners' needs for accommodation and safety, a local Johannesburg church, the Central Methodist Church (CMC), reached out to immigrants fleeing from areas where attacks occurred by providing accommodation to foreigners inside the church. Under the leadership of Bishop Paul Verryn, the church was hastily converted into a living space where refugees could reside. This occurred amidst a lack of response from the South African government at the time to manage its refugee population, preferring to follow a non-encampment refugee policy of promoting selfreliance (Crisp \& Kiragu, 2010). Unlike other countries, South Africa tends not to house migrants in camps. This results in refugees entering mostly urban areas and having to find places of refuge themselves. Instead the government attempts to process immigration applications by opening refugee centres in areas where high numbers of refugees and migrants are encountered. In June 2011 one such refugee reception centre in Johannesburg was closed down, making it more difficult for migrants to lodge migration applications, as reported by Mthathi (2011). The service provided by CMC is thus an example of critical protection services provided by community organisations to alleviate the living conditions of refugee populations. The 2008 incidents of xenophobia contributed to an influx of refugees, who flocked to the church in their hundreds. Conditions in the church were far from comfortable and less than suitable for accommodating large numbers of people. Basic services consisting of bedding and blankets as well as daily meals were provided to residents at the church, while the church attempted to support migrants with documentation issues. At times more than 3500 people reportedly reside in the church, whilst some residents leave the church once they find a job or alternative and more suitable accommodation. The crowded conditions have resulted in some residents sleeping outside the church on the pavement. Security has been an ever-present problem and criminal activity inside the church, such as theft and alleged rape, has been noted. Other issues such as insufficient living space, poor ablution facilities and inadequate social services are real at the church. External hazards such as police action against refugees who do not have papers, protests from external businesses in the area regarding overcrowding concerns and competitive business practices by migrants, and poor services from government departments are frequently reported. This emergency service has been provided since 2008 and continues to date. The church effort may thus be regarded as a humanitarian response to accommodate and shelter refugees and migrants in view of the risks of xenophobia and lack of governmental response. Media reports in 2008 indicate the church was often at the centre of disputes with government and, as indicated, businesses in the immediate environment.

During 2008 the Department of Social Work at the University of Johannesburg became involved at the Central Methodist Church (CMC) to conduct research on this vulnerable population. The author utilised fourth-year Social Work students to conduct research on the risk and protective factors inherent in the church environment as an emergency care centre for foreigners in inner city Johannesburg. The main goal of this article is to develop a practice perspective on migrants in the CMC as practice context and then to provide guidelines for social intervention in this client system. Some questions that need to be answered in this article are: What are the characteristics of the client system of 
migrants as a client population? How should we as social workers view the CMC environment as client system? And in what kind of direction should we can move towards intervention?

\section{LITERATURE STUDY ON NEEDS OF REFUGEES IN FOREIGN COUNTRIES}

\section{Definition of the term "migration"}

In this article the term "migration" refers to patterns of movement of people within but also between different countries for a variety of reasons, but mostly to settle in another country (Castles \& Miller, 2003:2; Guild \& Van Selm, 2005). Among reasons for migrating are alternative employment opportunities as fuelled by greater movement in products, capital and labour requirements, while social reasons for moving include unsafe living conditions or political instability; the latter is frequently referred to as coerced or forced migration (Kok, Gelderblom, Oucho \& Van Zyl, 2006:6). This group can be referred to as refugees, since they have left specifically for political reasons or life-threatening conditions related to their political convictions or affiliations, race and culture. It is assumed that this category can also be described as asylum seekers because they have left a country of conflict for a harbouring country. It is assumed the population of inhabitants at CMC may be composed of both migrants and asylum seekers. Both these groups in the case of this study consist of people who may or may not have the necessary travel documentation and have entered the borders without legitimate documentation.

\section{Attitudes towards migration in the macro environment}

From a political and structural perspective, Crush and Dodsen (2007:440) argue that the South African government is inherently anti-immigration orientated, as is evidenced by the slow response in changing outdated discriminatory immigration legislation. It is argued that the current Immigration Amendment Act (Republic of South Africa, 2007) does not effectively reflect the human rights focus of the country and is in many respects biased towards males (Crush \& Dodsen, 2007:442). The current increase in undocumented immigration is partly facilitated by a combination of a booming false documentation culture, a willingness to exploit immigrants economically, and porous borders that promote uncontrolled access into the country (Crush \& Dodsen, 2007:443). Rugunanan and Smit (2012:709) indicate that migrants, termed "illegal immigrants", find it difficult to obtain immigration documentation or refugee status as they are stopped by a Department of Home Affairs that often takes more than six months to process documentation that could be done in six weeks. The use of migrant labour is not uncommon in South Africa and many foreign labourers from countries such as Zimbabwe, Malawi, Lesotho were used historically to work in the South African gold mines. This form of migrant labour was organised and well documented, yet it was temporary and did not necessarily promote immigration. 


\section{A systems perspective}

Theoretically different models can be cited to explain the migration phenomenon. In this article I will only focus on those that facilitate a social work practice that is relevant to understanding the migration phenomenon. Castles and Miller (2003:27) propose a migration systems theory that explains migration as movement initiated as a result of prior links between sending and receiving countries. These links may be political, economic or historical, but they are characterised by a transactional history of collaboration and support. Migration in this sense is initiated by transactions at macro (state level), mezzo (intermediate mechanisms such as agencies) or micro level, such as individual social networks and support. Gelderblom (in Kok et al., 2006) argues that motivations for migration are informed by perceptions regarding spatial arrangements in the country of origin and the new country. Often termed push and pull factors, these factors influence migration patterns and determine the decision to move. Push factors mostly refer to negative or risk factors such as political and economic insecurity in the home country, whilst factors such as returning a favour or expecting the return of a favour, or perceived economic advantages, opportunity, better wages, good services or social connections are regarded as pull factors towards the destination country. Most of the above spatial arrangements can be explained by micro and macro economic theories; however Gelderblom (in Kok et al., 2006:274) asserts that migration is often a family decision associated with patriarchal decision-making patterns, especially if the reason for migrating is related to job opportunities, land utility issues or micro-economic gain. The migrant frequently stays in the receiving country until such time as enough money has been raised to go back home. The final decision to move remains a household decision motivated more by social considerations regarding family welfare than by purely economic considerations. Especially where families are poor and several members have to work to contribute to income, this decision is not made by a single person alone but by all the wage earners jointly. Migration decisions bring power issues to the fore and women are often discriminated against as they have less power to influence migration decisions. The existence of informal links and networks created by migrants themselves prior to the migration or as a result of migration by others then becomes an important pull factor as there is mutual support available. Castles and Miller (2003) further regard family and community in the receiving country as important links in these informal networks, whilst mezzo-level structures fulfil mediation roles between migrants and political and economic authorities. The family system plays a central role as a micro-level support system, often providing shelter, coping with bureaucratic procedures and emotional support. Families often remain behind at home until such time as resettlement appears a workable solution.

From this perspective migration is a self-perpetuating process in that migration increases in tempo once early migrants have effectively settled in the new country and have gained economic capacity and established community in order to let family members come over (Kok et al., 2006:285). 


\section{RISK AND PROTECTIVE FACTORS}

At the micro level of day-to-day functioning, a risk and resilience perspective on migration enables the researcher to understand the complex interplay between multiple migration factors as well as risk and protective factors in the lives of migrants. This perspective assumes that people have a remarkable capacity to withstand and overcome adverse and difficult events in their lives and adapt to complex circumstances (Greene, 2007:4). Understanding the resilience patterns of migrants, especially during the early stages of settlement, may assist social workers in understanding how migrants settle and cope with living conditions in the receiving country.

\section{Protective factors}

In an article on secondary migration of African migrants into the USA Weine, Hoffman, Ware, Tugenberg, Hakizimana, Dahnweigh, Currie and Wagner (2011) found that a sense of community and being close to people similar to oneself within the boundaries of a community or a refugee camp environment could be considered one of the most powerful protective factors in the lives of refugees during initial migration. They defined protective factors as "family and ecological characteristics that stop, delay, or diminish negative individual behavioral and mental health consequences for youth or adult family members". They further distinguished between resources within families such as parenting, supervision of children and communication styles, and out-of-family factors such as a sense of community and perceived support from the church or other families. In support of the migrations systems model discussed earlier, the informal social support systems in the receiving country play a vital protective role for new migrants.

\section{Risk factors}

Specific risk factors are indicated as conditions associated with their settlement such as poverty, unemployment, discrimination, family, social and cultural dislocation (Weine et al., 2011:31). Migrant vulnerability increases when foreigners arrive and live in areas that are already dangerous and unsafe. This increases the risk of falling victim to ordinary crime. Inner-city Johannesburg, such as where the CMC is located, is a particularly vulnerable area ravaged by crime.

Migrants often feel vulnerable and unsupported by the local population. The xenophobic attitude of locals is often racially determined but it does not come exclusively from whites, but rather from blacks towards other blacks. African refugees are often surprised by fellow African racial attitudes. Xenophobia is not aimed at males only; women are subjected to xenophobic violence at least as often as males (Sigsworth, Ngwane \& Pino, 2008:8). It is argued that xenophobia in South Africa has its origins in history, specifically from the earlier segregation and later apartheid systems that encouraged divisions between population groups and promoted exclusion of foreigners (Harris, 2001). Xenophobia can be defined as "the attitudes, prejudices and behaviour that reject, exclude and often vilify persons, based on the perception that they are outsiders or foreigners to the community, society or national identity" (Lesser, Fernández-Alfaro, Cowie, \& Brunin, 2006:494). Xenophobia is often inter-related with the economic exploitation of foreigners by locals who utilise the foreigners' position of vulnerability 
for economic reasons. Much economic exploitation occurs during or after the migrant has entered the borders of the destination country. Different kinds of migrant exploitation have been documented, such as institutions that don't allow foreigners to open bank accounts without documentation. Informally, public verbal abuse and common violence are different forms of discrimination against foreigners (Rugunanan \& Smit, 2012:709). Castles and Miller (2003:28) attribute the exploitation of migrants to the development of a "migrant industry", one where helpers or facilitators emerge to assist migrants in re-settlement, but unfortunately exploiters emerge as well to contribute to the risk profile of migrants. For the individual the social consequences of migration are often personal insecurity, gender discrimination and inequality as well as economic and social obstacles that in essence hinder their social development (Idris, 2012:31). Lack of institutional response such as slow reactions by police is another form of xenophobia that discourages foreigners from reporting crime. It can be concluded that the environment entered by a foreign migrant is less than friendly and all but receptive. Castles and Miller (2003:35) assert that an associated risk related to migration is the emergence of racism or ethnocentrism, where cultural and/or phenotype differences are identified and focused upon by the dominating culture.

\section{Social inclusion/exclusion perspective}

A social inclusion/exclusion perspective provides valuable insights into the underlying dynamics of migration, if cognisance is taken of behavioural characteristics of the dominating or in-group versus the migrant or out-groups. Esses et al. (2005:323) assert that individuals who define the local culture as paramount and exclusionary are more likely to be negative and respond less favourably to immigrants. Furthermore, these authors maintain that different subgroups in society may differ systematically from one another in the way they view factors of differentiation. This may be true of South African subgroups that may transfer existing prejudices against other race groups to foreigners. Otherness and differentiation are major risks that migrants responded to by becoming "invisible" to hide either from the police, authorities or other ethnic groups or from the urban community (Anderson, 2012). "Invisible" behaviour may be associated with "acculturative stress" (Samuel, 2009:18), a reaction stemming from being divorced from one's familiar surroundings and finding ones existing coping mechanisms insufficient to deal with current realities. Such lack of coping contributes to responses such as extreme depression (Hepworth et al., 2013:196). Invisible behaviour furthermore prevents migrants and refugees from accessing services, as reported by Schockaert (2010). The risk of being detected, or being identified, is simply too great. Therefore refugees and migrants prefer to suffer health and psychological risks and social exclusion for fear of being detected. These can be termed self-defeating responses to social exclusion and they diminish effective problem solving (Abrams et al., 2005:30).

In the light of the theories discussed so far, cognisance should be taken of the characteristics of social support networks in receiving and supporting migrants. Picket and Brewer (in Abrams et al., 2005:90) maintain that individuals require connectedness and belonging with others in order to function properly. They further indicate the adverse consequences for health, adjustment and wellbeing if such attachment to a group does not occur. They further 
explain the consequences of the lack of group attachment as contributing to distress, depression and personal insecurity. Twenge and Baumeister (in Abrams et al., 2005:36) provide evidence indicating that social exclusion is positively associated with aggression and self-defeating behaviour as negative consequence of exclusion. Furthermore new group formation and inclusion are enhanced when individuals contrast themselves in relation to other groups. In contrast to the "welcoming" approach that assumes inclusion and acculturation, Bigo (in Guild \& Van Selm, 2005) notes the societal perceptions of immigrants as a threat to the welfare state and at most a threat to national security. It is argued that such perceptions subtly or explicitly find their way into policies and intelligence activities and are more prominent during times of crisis.

The above theories thus provide an understanding of the living conditions and wellbeing issues of migrants after their arrival in the receiving country. These perspectives may be useful towards the determination of a social work intervention strategy.

\section{EMPIRICAL STUDY}

In order to further elaborate on the wellbeing issues facing migrants, a case study is provided as illustration. During 2010 the author conducted a study among the residing migrant population at the Central Methodist church (CMC) in Johannesburg. This study aimed to describe perceptions of refugees residing at the church mainly in respect of three areas: their demographic characteristics and migration background; their perceptions regarding their own position and relative safety in the receiving country; and thirdly, their perceptions regarding intermediary services and informal social support rendered by the church. This study facilitates the formulation of a social work practice perspective and understanding of migrant social issues.

\section{Method}

A quantitative study using a cross-sectional survey method was utilised involving a sample of 106 respondents, initially selected purposively (only people who lived at the church were selected) and complemented by accidental selection techniques during a one-day period of data collection. The research population was demarcated geographically as consisting of residents temporarily living at the $\mathrm{CMC}$ at the time of study. Since the church accommodates South African citizens as well, participants were specifically asked to indicate their migrant status in order to qualify for participation. In this way care was taken to ensure that participants would be drawn from refugees/asylum seekers and not some other group. The researcher took time to explain the study to potential participants and specifically indicated the benefits of the research for improving conditions of care and support, and not fulfilling expectations regarding the participants' immigration status. Since the research population was not static but consistently changing as migrants joined and then left the church, it was not possible to judge the exact size of the population or its composition at the time of the study. Although availability sampling is often not considered useful for generalisation purposes, it was considered useful in this study since it could be combined with a quota approach utilising gender as a key variable (Grinnell \& Unrau, 2008:151-152). It was estimated that on average there were some 3500 refugees residing at the church at the time of the study (Verryn, 2009). Of this number about two thirds were 
reportedly male, the remainder female. This allowed the researcher to set the sample size at about 100 to obtain a 3\% representation and work towards obtaining the gender split as indicated above. The data were collected during early evening, a time when most residents who left in search for work during the day or who had a job returned to the church for the evening. This was done to minimise the chances of sample bias. Respondents were informed and prepared for the study prior to the actual data collection. The above procedures were implemented to achieve some level of sampling control, ensure adherence to minimum levels of representation and promote sample sufficiency. To further refine the sampling process, potential respondents were approached by fieldworkers and invited to participate. Field workers would continue sampling until the gender quota was reached. Informed consent was used as the principle for participation, whilst confidentiality and anonymity measures were put in place to ensure objectivity in the data. A self-developed questionnaire consisting of a biographical section and two sections of perceptual questions was utilised as the data-collection instrument. Questions called for respondents' perceptions regarding various aspects of the services provided at the church. The sampling frame followed was consistent with measures proposed by Grinnell and Unrau (2008:154-156) for ensuring sampling adequacy and quality. The main limitation in sampling was that the exact size of the population at the time of data collection was not known and had to be estimated. Secondly, the quality of the sample may have been undermined by the accidental nature of sampling that occurred in the setting. It was also difficult to ensure sufficient privacy for conducting interviews and this may have compromised some of the responses.

\section{ANALYSIS PROCEDURE}

The analysis was conducted at a descriptive level because of the choice of design for the study and the relative measures of accuracy built into the sampling plan. Furthermore, most of the data were nominal and categorical, while perceptual questions were mostly ordinal and based on a five-point Likert scale response system; thus the analysis consisted of bivariate item-level comparisons only by means of cross-tabulations and Pearson's ChiSquare test. In order to get a useful result and reduce the risk of Type II errors the statistical power of the study was set at $80 \%$, the minimum effect size (Cramer's V) was set at .275 and a required sample minimum of 88. A priori calculations were performed by means of the GPOWER statistical power analysis calculator (Faul, 1992). Test results with Alpha values of 0.05 were reported, while a $20 \%$ low cell count criterion was used for rejecting invalid tests (Grinnell \& Unrau, 2008:503).

\section{RESULTS}

\section{Demographic statistics}

A sample of 106 was realised. Seventy per cent of respondents were male and $30 \%$ female. The gender distribution corresponds to the two-thirds males in the quota requirement as planned above, but is slightly different from the gender distribution in a study by McDonald et al., 2000:819) on migrants from three African countries, where a 60/40 split was obtained. Sixty nine per cent regarded themselves as single, $24 \%$ were married and $6.6 \%$ were living together with a partner. The youngest respondent was 15 and the oldest 89 . This sample is skewed towards younger people, with the mean age of respondents being 26 
years, as indicated in Figure 1. The majority (69\%) were not married at the time, while $24 \%$ were married. About half of respondents were supporting family back home, and in $20 \%$ of cases migrants brought their family along with them. This indicates migrants at CMC to be mostly representatives of families who remained behind in the country of origin. In their study of female migrants Rugunanan and Smit (2012:711) found them to have migrated without their men, while men were here without their families. Respondents in this sample were predominantly from Zimbabwe or Zambia, countries characterised by political instability, corruption and infrastructural collapse (Klotz, 2000:839). This corresponds with trends observed by Crisp and Kiragu (2010), who add that this pattern has recently changed, with many refugees arriving from Somalia and the Horn of Africa.

\section{FIGURE 1}

\section{AGE DISTRIBUTION OF SAMPLE}

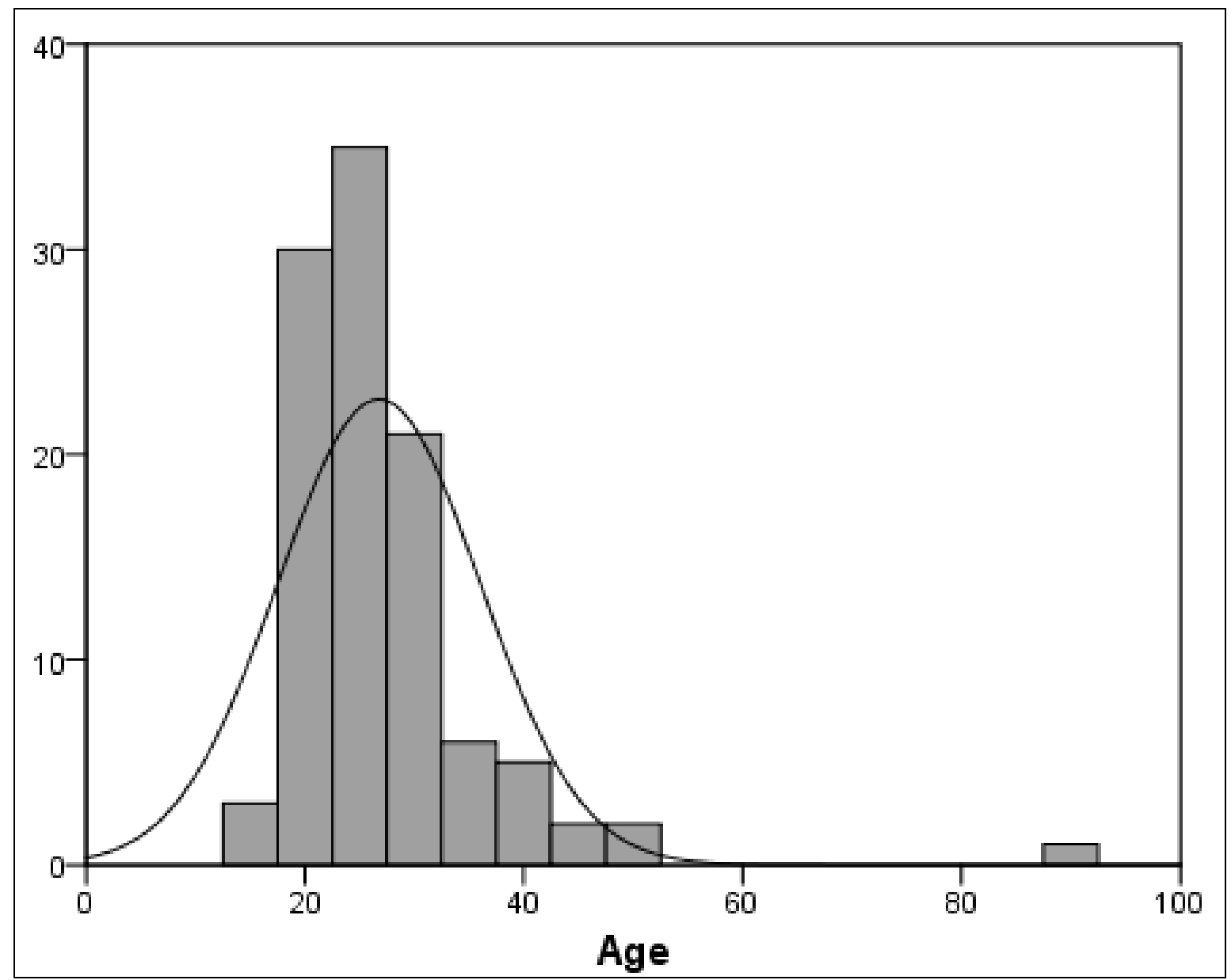

The sample is composed of predominantly younger refugees and migrants who left their families behind; most came by themselves and tended to see the church as a temporary shelter and place to stay until they find employment (Figure 1). The church is a loosely structured system with a temporary character, not a place where migrants intend to settle. Relationships formed at the church are likely to be temporary and functional, and do not foster a sense of community. 


\section{Reasons for coming to South Africa}

\section{Push Factors}

Sixty four per cent of respondents were certain about their reasons for coming here. Males clearly knew the original reason that they left their home country, while females were less clear about these reasons $(\chi 2(2, \mathrm{~N}=101)=7.329, \mathrm{p}=.026 ; \phi=.269)$, probably because they would be here as a result of their male partner's decision rather than their own. This finding suggests a potential risk of gender-based oppression, as observed from the literature. Respondents' primary reasons for coming to South Africa ranged from finding employment (33\%) and the prospect of a better life in South Africa (28\%), to getting away from a threatening family situation back home $(27 \%)$. This seemed consistent with what Harris (2001:60) described, namely that migrants are pushed by multiple factors such as economic, political and personal safety reasons. Most respondents saw their move to Johannesburg as more than just finding temporary shelter. A few respondents came to the church for spiritual reasons, most hoped to find care for their children or social support from others. Most respondents came to CMC to find temporary shelter until they managed to settle elsewhere in more permanent conditions and find employment. Fourty six per cent of respondents regarded themselves as migrants who had the necessary immigration papers to stay in the country, while $22 \%$ described themselves as refugees who did not have the necessary paperwork. Some significant differences were found between the views of ultra-short-term migrants (one week to four months) and those that had stayed at the church for more than six months.

\section{Pull factors}

Thirty three per cent of respondents indicated migrating to South Africa primarily to find employment. This group can be described per definition as migrants, since their primary motivation is economic prosperity (IFSW, 2010; Kok et al., 2006:48). Twenty eight per cent of respondents indicated the promise of a good life and future as their most prominent pull factor for migrating. An equally large percentage $(25 \%)$ of respondents perceived their lives as having improved since they came here. This implied improved health care and satisfaction with their current circumstances.

In contrast, $70 \%$ felt prospects for employment had decreased since they came here. This supports what Harris (2001:7) found, namely that refugees are often disillusioned about the new country in that the employment opportunities they were looking for disintegrated as they faced the reality of the South African situation. Harris further argues that migrants always regard their stay in the new country as only a temporary arrangement to be terminated if things don't work out.

\section{Exposure to xenophobic events}

As has been shown in the literature study in this article, the way refugees are received in the host country plays an important role in the refugees' attitude towards the new country and the future. In this regard reception in the host country may be reflected in the exposure of migrants to violence, xenophobic events, crime and the nature of immigration processes. For purposes of this study it was important to establish if respondents had been exposed to any threatening xenophobic events since their arrival in 
the country, as this would indicate social wellbeing and support. This would allow the researcher to determine the effect of such event as an external risk factor on the perceptions of respondents. Twenty eight per cent of respondents had been exposed to incidents that can be described as aggression and exclusion on the basis of otherness. About $9 \%$ of all respondents suffered injuries as a result of a direct form of attack (not necessarily xenophobic in nature and including criminal events). Half (50\%) of respondents were exposed to abusive situations in which power played a role and which left them traumatised. Fourty per cent had been confronted by a police officer, while a third of respondents $(33 \%)$ reported having been violently confronted by another person on the street. The duration of stay at the church made it more likely for refugees to have had contact with the police, with exposure chances increasing significantly for those staying longer than two months $\left(\chi^{2}(1, \mathrm{~N}=94)=15.685, \mathrm{p}=.019 \phi=.254\right)$. In addition, respondents who had been confronted by the police felt more vulnerable and threatened than those who had not been confronted. Being confronted by policemen was perceived as reducing one's chances of finding employment and could mean the termination of one's stay in the country. A large proportion of refugees who had been confronted by police perceived South Africans to have supported them during these difficult times. Sigsworth et al. (2008:21) report that in surveys conducted on migrant respondents, about a third of respondents reported their relationship with South Africans as good.

Sixty per cent felt insecure because of an inherent risk or threat in the environment, while an equally large proportion felt women and children were not secure at the church. About half of the sample became more insecure the longer they stayed at the church, and $66 \%$ were more concerned about their personal security now than before they arrived at the church. In contrast and in spite of loss of personal security, longer-term residents were more optimistic about future prospects than short-term residents. None of these results were gender-differentiated. This is probably because the longer migrants stayed in the country, the more likely they would have found employment or settled in the new country. According to our theoretical perspective above, the chances of social inclusion may increase over time as social support linkages are formed. Staying longer than two months was associated with feeling more optimistic about the future, having better employment prospects and a perception that the church assisted respondents. The study revealed the duration of stay at the church was influenced by family events/crisis back home in the absence of the respondent. Overall the duration of stay at the church was a protective factor to migrants. These findings are illustrated in Table 1.

The majority of respondents $(80 \%)$, however, did not have any contact with a government official while staying at the CMC.

\section{Level of support in country of origin}

Thirty four per cent indicated that they had been physically, sexually or emotionally abused in their home country prior to entering the new country. Such victims of abuse felt more negative about the church's support efforts than non-victims; they were less likely to feel respected by those responsible for helping them; they had more health problems; they were unhappy about their decision to come here; they felt the church was unable to help them; and they were significantly more likely to experience feelings of loneliness and lack of support (see Table 1 
for findings). It can thus be concluded that the victimised group in particular is more vulnerable and at higher risk of experiencing psychological symptoms related to adjustment in the new country. This finding furthermore emphasises the effects of prolonged psychological symptoms as a result of previous trauma and shows the effect of previous trauma on adjustment capability during migration.

TABLE 1

EMPIRICAL RESULTS OF STUDY

\begin{tabular}{|l|l|l|l|l|l|l|}
\hline Independent Variable & Dependent Variable & $\chi^{\mathbf{1}}$ & $\mathbf{N}$ & $\mathbf{d f}$ & $\mathbf{p}^{\mathbf{2}}$ & $\boldsymbol{\phi}^{\mathbf{3}}$ \\
\hline \multirow{5}{*}{ Duration of stay at CMC } & CMC helps people find jobs & 10.166 & 104 & 2 & .006 & .313 \\
\cline { 2 - 7 } & Hope for a bright future & 6.579 & 102 & 2 & .037 & .254 \\
\cline { 2 - 7 } & $\begin{array}{l}\text { Death of family member at } \\
\text { home }\end{array}$ & 6.508 & 104 & 2 & .039 & .250 \\
\hline Being a victim of abuse & Feeling respected & 11.600 & 97 & 2 & .003 & .346 \\
\cline { 2 - 7 } & CMC listening to need? & 11.950 & 98 & 2 & .003 & .349 \\
\cline { 2 - 7 } & Has your health improved? & 9.777 & 95 & 2 & .008 & .321 \\
\cline { 2 - 7 } & $\begin{array}{l}\text { Level of happiness with } \\
\text { coming here? }\end{array}$ & 7.517 & 96 & 2 & .023 & .280 \\
\cline { 2 - 7 } & $\begin{array}{l}\text { Feeling supported by others in } \\
\text { similar situation }\end{array}$ & 6.705 & 96 & 2 & .035 & .264 \\
\hline \multirow{2}{*}{$\begin{array}{l}\text { Being confronted by a } \\
\text { policeman }\end{array}$} & $\begin{array}{l}\text { Feeling threatened by external } \\
\text { things }\end{array}$ & 7.328 & 94 & 2 & .026 & .279 \\
\cline { 2 - 7 } & $\begin{array}{l}\text { Role of church to help people } \\
\text { find jobs }\end{array}$ & 7.114 & 93 & 2 & .029 & .277 \\
\hline
\end{tabular}

In general and irrespective of whether respondents received social support from locals after falling victim to trauma, some $63 \%$ of respondents still felt unsupported and rejected by South Africans. It does appear that migrants are confronted by attitudes of social exclusion.

\section{Social support as protective factor}

About half of respondents left their home country without their families in search of better employment opportunities and a brighter future. They came on behalf of the family and intended bringing their families once they had settled. This group was decisively more positive about the church environment as secure place for one's family, women and children $(\chi 2(2, \mathrm{~N}=99)=10.984, \mathrm{p}=.004 ; \phi=.333)$. This group was more concerned about external threats and risks in the new environment than those without strong family ties $(\chi 2(2, \mathrm{~N}=98)=6.125, \mathrm{p}=.047 ; \phi=.250)$. It appears that strong social support back home contributed to better adjustment in the church as place of safety.

\footnotetext{
${ }^{1}$ Chi-Square value.

${ }^{2}$ Probability or significance.

${ }^{3}$ Cramer's V value indicating effect size of Chi Square test result.
} 
In contrast Sigsworth et al. (2008:15) found that migrant women they interviewed who were subjected to continuous ethnic and political violence at home remained deeply concerned about their families back home and struggled to adjust. In many of these cases family members were killed or harmed as a result of these actions, increasing the concerns of refugees. This study found that refugees who left their home country because their lives were threatened (the presence of strong push factors) made sure that they gained information on the host country and the CMC before they left. This group was better prepared for the new country than others who did not come here as a result of any threat $(\chi 2(2, \mathrm{~N}=91)=15.635, \mathrm{p}=.000 ; \phi=.415)$.

\section{The church as social support system}

Was the church regarded as an important emotional and social support system? Males regarded the church as less sympathetic towards them compared to females, who perceived the church community to be more willing to listen to their needs ( $\chi^{2}(2, \mathrm{~N}=$ $105)=5.879, \mathrm{p}=.053 ; \phi=.237)$. Females were more optimistic about the supportive value of the church community and felt that church services effectively reached those in need $\left(\chi^{2}(4, \mathrm{~N}=104)=10.554, \mathrm{p}=.032 ; \phi=.319\right)$. The church succeeded in reaching out to those who made use of the church as a place of shelter, but was less effective in helping those who looked for employment. It was significant to note that those who felt women and children were secure at the church were generally more optimistic about the church, about the role and support of government and the ability of the church to carry on in spite of governmental influences. This finding suggests migrant women did find support in the services provided by the church, more so than males. The church seemed to fulfil a protective role by providing basic food and shelter care for migrant women and children. Males appeared to be less concerned about the church as social support system, but used the church as a base for finding employment. In this regard males did not regard the church as that helpful. Anderson (2012) indicates that makeshift urban care centres such as CMC are characterised by lack of a sense of community. This is attributable to the extreme diversity found in urban contexts, environmental risks and threats, and an attitude of convenience, using the centre as a temporary shelter.

\section{DISCUSSION}

This research provides more insight into the motivations and living conditions of refugees, immigrants and asylum seekers in a relatively confined temporary spatial arrangement of a church in the middle of Johannesburg. Specifically the study confirmed risk and resilience factors as found by Weine et al. (2011). Specific aspects that were confirmed are:

- Migrants were more exposed to violent public and official response in the host country as confirmed by Sigsworth et al. (2008:33-37);

- Migrants were vulnerable to being arrested or questioned by police or public officials about their official papers (Valji, 2003:5,31). This suggests that immigration is regarded as unwanted; 
- Migrants appear to be unsupported and feel unprotected, more so if they had been abused in some way (Harris, 2001:12). Generally, victims of either xenophobia or other abusive events regarded the church as less effective in providing emotional support;

- Migrants who are dislodged from their families of origin have less chance of adjusting to their new circumstances than those without strong family ties or who had their family with them (Crush \& Dodsen, 2007:449). The migrant labour phenomenon, characteristic of South Africa's past, is being blamed for this phenomenon, where families are left behind by the migrant in search of employment in the host country. However, this trend is not uncommon to migration patterns in other contexts (Rugunanan \& Smit, 2012:711; Weine et al., 2011);

- Single persons who came without their families had a better chance to adjust to the new circumstances and were less concerned about security issues than those who had their families with them. Migrants with families back home were more consistently concerned about the wellbeing of their families compared to those who had their families with them. Having the family with them provides a greater sense of support than being alone. Refugees should not be seen as individuals, but rather as integrated members of families and communities who continue to have a need for familial and cultural contact;

- The adjustment period for refugees appears to be about two months, after which refugees seem to become more optimistic about the future and their job prospects improve;

- The church effectively acts as a functional support system providing temporary inclusion to migrants from other countries. As a makeshift housing arrangement the church is successful in providing food and shelter to this group of migrants. Far from providing ideal housing conditions, the church still managed to play an active role in taking care of foreigners. Women and children found more psychological support and felt more secure in the church as care system. However, the church seemed less successful as employment broker in the opinion of males;

- In reflecting upon the role of community-based organisations in providing care for migrants, one needs to understand the circumstances in which such organisations operate. The CMC is situated in an urban environment characterised by urban decay, violence and crime. The church environment itself is not suitable for housing migrants and as an open environment is likely to be vulnerable. Efforts by the church to secure its premises are at least partially effective and provide some form of secure living. The church effort reflected a community response to a lack of governmental response to a growing migration situation. Evidence shows this situation has not changed much since 2008 .

\section{CONCLUSIONS AND RECOMMENDATIONS}

Migration across Africa is a long-standing and well-described phenomenon, and much is already known about its dynamics and its interaction with state immigration policy as well as xenophobic attitudes in South Africa. Despite the growing body of knowledge on 
this topic in fields such as political science, sociology and demographics, the role of social work in dealing with migrants and their social wellbeing is not well described. Social workers appear to be engaged in dealing with a different range of desperate situations and frequently appear not have the capacity to deal with migrant issues as well. Although the findings of this study cannot by any means be generalised beyond the confines of this particular community, the study does provide more insight into and understanding of the living conditions, social concerns and systemic factors of the migration phenomenon and how it should be understood from an eco-systemic and resilience perspective.

Circumstances at the church presented a picture of mixed fortunes. Not only was it found that the refugee population consisted of younger people, often single, but the church was not seen as being effective in addressing the socio-emotional needs of social cohesion, a sense of community and inclusion. Victims of forms of abuse such as xenophobic attacks could use the church as a shelter, but could not expect to receive counselling or any direct supportive services. Women were more optimistic in this regard, as they regarded the church as more helpful and supportive of their needs. Some commonalities have been observed with what happens in other refugee communities as confirmed by literature (Makiena, 2010:191). Similar to other migrant situations, employment and the prospect of starting a new life in a wealthier country seemed to be the main reason for coming to South Africa, a drive that was frequently countered by the hostile attitudes of locals. It could not be conclusively confirmed that most migrants at the church were refugees who fled from unstable political circumstances in their own countries. Instead, migrants appeared to migrate more for economic reasons than political ones. This confirms reports by Crisp and Kiragu (2010) referring to the influx of migrants as "survival migration".

The study has shown that this population is as much exposed to the realities of xenophobia as migrants in other areas. Residents at the church have been exposed to attacks and crimes at least as much as locals are, while a significant proportion of church residents were victims of xenophobic attacks. These incidents have to be viewed carefully from a social inclusion/exclusion perspective as facilitation of inclusion could be a typical domain of intervention. From this perspective the church as a temporary refugee accommodation does not support the notion of inclusion; because it stands out as a system specifically catering for a specific group, it does not blend in with the environment.

Refugees make temporary use of the church as a place of safety and shelter, and do not intend staying there for long periods of time. A fairly large proportion of refugees stay at the church for longer than two months, and although this trend was found to have a positive effect on their overall social adjustment and employment prospects, it puts severe pressure on already overcrowded facilities that have in the first place not been designed to serve as accommodation facilities. Other non-immigrant or local migrants were found at the church as well, as these groups saw an opportunity to benefit from the church and its services. The ability to stay for longer periods is considered a protective factor for migrants. 
It is of particular concern that a fairly high percentage of refugees has been subjected to xenophobic and other traumatic events that clearly influence the way they perceive their surroundings and their prospects for adjustment to the new country. It is of equal concern that a high percentage of refugees lives in fear of being exposed to violence in their current environments. Family ties are very important to migrants and being away from one's family contributes largely to adjustment problems. Was it better for the migrants to have their family with them? In some respects the families' presence contributed to emotional support, but the presence of families at the church made them more vulnerable to abuse and exposure to environmental threats.

The Central Methodist Church frequently attracted media attention during 2008-2009 and the church's head, Bishop Verryn, was often locked in tight negotiations with the government regarding circumstances at the church. This political debacle highlighted problems in South Africa's management strategy of immigrants, which remains a cause for concern, as is evidenced by the significant number of migrants who have been exposed to police officers and experience problems with immigration documentation. This study followed in the wake of this public focus on conditions in temporary shelters and that may have contributed to feelings of insecurity. About half of respondents regarded the church as a place of emotional support or where one's social problems are addressed. The remainder of respondents saw the church only as a temporary residence, where the main emphasis was on getting food and blankets. It can be concluded that although the church addresses basic needs, it does not necessarily provide a socially secure and supportive environment to migrants similar to a community of cultural support. The church environment appears to be vulnerable to different kinds of crime and violence in spite of efforts to employ security staff for the protection of residents. In this regard the church can be regarded as a primary settlement agency, from where migrants would move to secondary places of settlement in other communities (Weine et al., 2011:29).

Assessing these findings against the International Federation for Social Work policy statements on migration and displaced persons (IFSW, 2010), it is clear that the area of migration is an often neglected practice area for social workers. At the micro level it is strongly argued that social work plays an important role in the following areas of migration.

- Assistance with settling in the new country, from reception to documentation, housing and employment issues is one aspect that requires social workers' attention. Trauma counselling is another area requiring development, as is evidenced by the relatively large population of traumatised persons in the church. Contact with families back home and re-unification with families may play an important role in a person's successful adjustment in the new country and mitigate risk. Although such intervention may be difficult to effect as a result of infrastructural capacity in the home country, it would be of benefit for refugees if relatives and family members were able to contact the church to search for family members. Social workers could assist with services in this regard. Similarly the provision of information in which key social issues in adjusting to the new country are addressed should be provided to 
migrants and refugees upon entering the new country, as recommended by the IFSW policy. From a risk and resilience perspective, social work interventions should focus on developing culture-specific communities where migrants can find support from their own cultural group. This can assist with their adjustment in the new society;

- The church as residential setting remains a less than ideal environment to house people. Its inadequate construction and the large numbers of people residing in the church are likely to produce unfavourable social conditions, as evidenced by the lack of social cohesion encountered in certain groups of this sample as well as the likelihood of abuse and lack of security. As a temporary measure it may perhaps hold, but in the long term it may prove to be physically and socially inadequate. The IFSW policy outlines accommodation issues, access to services, participation in voting, obtaining scholarships and opportunities accessible to the local population as key human rights issues that need to be addressed by social workers;

- A study by Polzer (2008) concluded that the welfare sector, and specifically the NGO sector, remains fragmented and limited in its response to migrants. Many services exclude non-citizens from their services and lack networking with organisations working on housing issues, food and basic health-care provision. Funding and lack of capacity are cited as the main reasons why those NGOs that do respond can do so only in a limited way. It is maintained that services, where provided, are limited to inner-city environments, with no services in rural areas. In spite of this, some $60 \%$ of migrants in Johannesburg maintained that they had not received any services from welfare organisations. Polzer further maintains that current accommodation arrangements are far from sufficient to house high volumes of migrants. She concludes that organisations such as churches are not equipped and do not have sufficient experience or capacity to effectively manage accommodation services to migrants;

- Lastly, civil society does not necessarily contribute to the successful integration of migrants into society or the promotion of their livelihoods (Polzer, 2008). Attitudes of xenophobia, exclusion from jobs, denial of accommodation on the risk side, and charity on the protective side, characterise the South African response to migrants.

Based on the findings of this article the following migration systems model can be formulated to assist with explaining the migration process and the risks associated with migration.

The migration systems model in Figure 2 consists of four stages of migration starting with the consideration or initiation phase, where the plan to migrate emerges. This phase may be informed by a number of risk factors that push migration, or pull factors based on an opportunity assessment of the new country. The second phase consists of the actual migration process characterised by its own risk factors associated with travelling to the new country. In the arrival phase primary adjustment to the new environment is not necessarily met with high levels of social support. The fourth phase of resettlement implies migrants leave the arrival shelter and move to a new settlement in pursuit of employment or association with family members who have already settled, or clan members. Different types of social connections are engaged with during secondary resettlement: "social links", which are informal and short-term contacts often involving formal systems in the host 
country; "bridging" type connections with members in the new community; and "social bonds" with family and clan. These connections facilitate integration and secondary social support to migrants (Pittaway, Muli \& Shteir, 2009).

\section{FIGURE 2}

MIGRATION SYSTEM MODEL

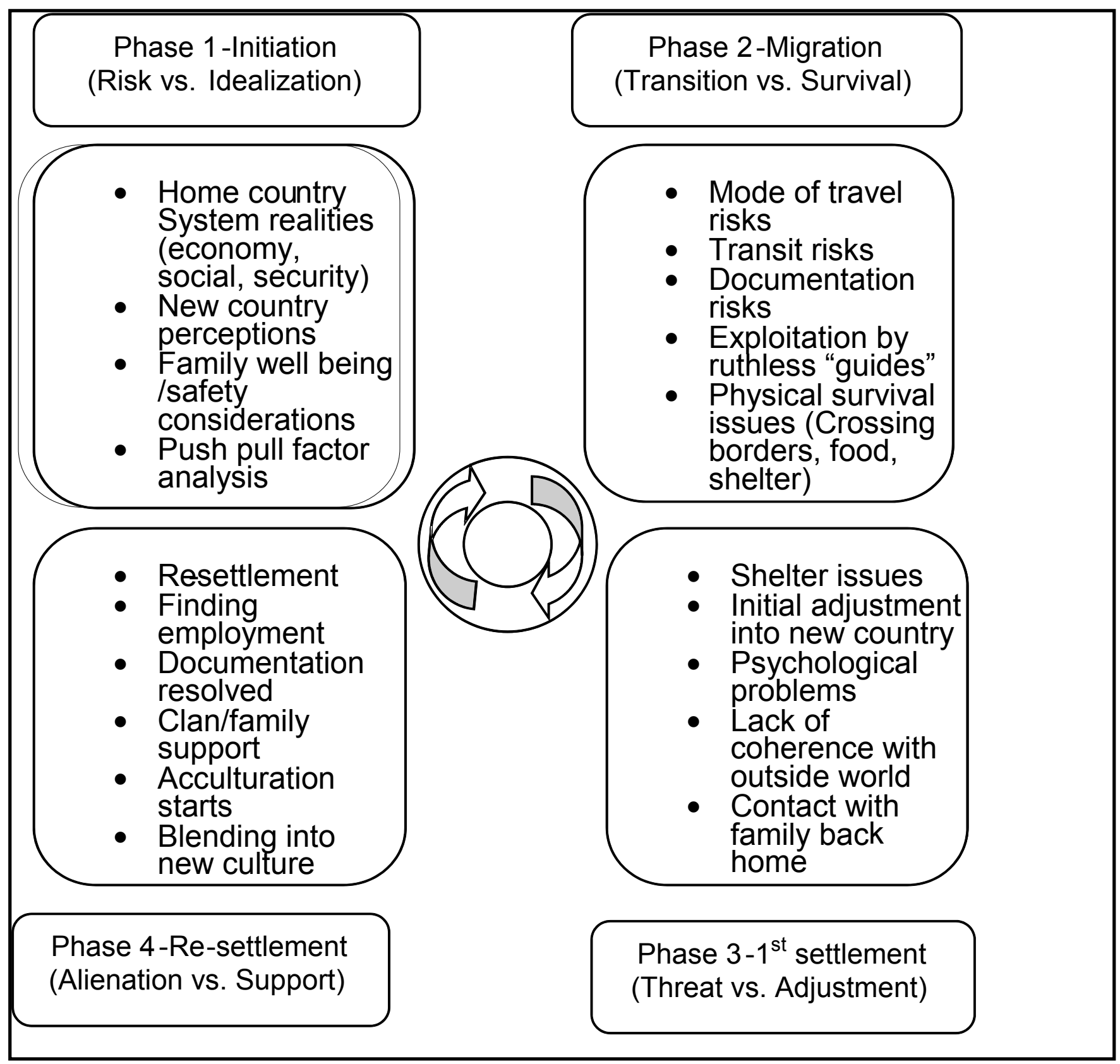

As indicated in this article, the church as protective environment has limited supportive capability to mediate the risks associated with arrival. In the last secondary settlement phase of migration, migrants will move to different communities, usually where family or cultural support groups reside, or a job opportunity is found. The migration system model provides information regarding critical tasks that need to be accomplished during the migration process that indicate the resilience of migrants. How effectively these tasks are accomplished determines the levels of protection and inclusion that are attained by the migrant. These tasks provide guidance to social workers on issues that have to be resolved 
during intervention. Kohli (2006) identified three domains of social work intervention, some of which correspond to those of the above model. Intervention should be focused upon making sense of the outside world upon the arrival of migrants; issues such as shelter, food and secure care; and assistance with documentation and making sense of the outside world are the priorities in this domain. Secondly, intervention should focus on selfmaintenance issues related to inner peace, adjustment and psychological health. Lastly, intervention should focus on connection issues associated with resettling, where migrants have to connect to a new society and make sense of their own role within this new world. According to the migrant system model, an assessment of the home country circumstances and relationship to family back home seems to be important.

This article proposed a migration system model for social work practice that incorporates risk and resilience factors; eco-systemic stresses and inclusion/exclusion factors. It provides guidance on potential assessment and intervention areas for direct work with migrants. Xenophobia was found to be a specific manifestation of cultural exclusion behaviour that is deeply embedded in the South African context. One of the main tasks to be accomplished by new migrants is overcoming exclusion and otherness and blending into society. This should be the key focus of social work efforts in assisting migrants.

\section{REFERENCES}

ABRAMS, D., HOGG, M. \& MARQUES, J. 2005. The social Psychology of inclusion and exclusion. New York: Psychology Press.

ANDERSON, J. 2012. Urban displacement and peacebuilding: an analysis of South African social cohesion interventions. Geneva, Switzerland: New issues in refugee research.

ANON. 2012. 2012 UNHCR country operations profile - South Africa. [Online] Available: http://www.unhcr.org/ cgi-bin/texis/vtx/page?page=49e485aa6\#.

CASTLES, S. \& MILLER, M.J. 2003. The age of migration. International population movements in the modern world. New York: Palgrave Macmillan.

CRISP, J. \& KIRAGU, E. 2010. Refugee protection and international migration: a review of UNHCR's role in Malawi, Mozambique and South Africa. Geneva, Switzerland: United Nations High Commissioner for Refugees.

CRUSH, J. \& DODSEN, B. 2007. Another lost decade: the failures of South Africa's post-apartheid migration Policy. Tijdschrift voor Economische en Sociale Geografie, 98(5):436-454.

ESSES, V., DOVIDIO, J., SEMENYA, A. \& JACKSON, L. 2005. Attitudes toward immigrants and immigration: the role of national and international identity. In: ABRAMS, D., HOGG, M. \& MARQUES, J. The social Psychology of inclusion and exclusion. New York: Psychology Press, 355.

FAUL, F.E.E. 1992. GPOWER: a priori, post-hoc, and compromise power analysis for MS-Dos. Bonn: s.n. 
GREENE, R. 2007. Social work practice: a risk and resilience perspective. Belmont CA: Thompson Brooks/Cole.

GRINNELL, R. \& UNRAU, Y. 2008. Social work research and evaluation, foundations of evidence-based practice. New York: Oxford University Press.

GUILD, E. \& VAN SELM, J. 2005. International migration and security, opportunities and challenges. New York: Routledge, Taylor \& Francis.

HARRIS, B. 2001. A foreign experience: violence, crime and xenophobia during South Africa's transition. Johannesburg: Violence and Transition Series.

HEPWORTH, D., ROONEY, R., ROONEY, G. \& STROM-GOTTFRIED, K. 2013. Direct social work practice. Canada: Brooks/Cole.

IDRIS, A. 2012. Malaysia and forced migration. Intellectual Discourse, 20(1):31-54.

IFSW, 2010. International Federation of Social Workers. [Online] Available: http://ifsw. org/policies/displaced-persons/ [Accessed: 22/09/2012].

KLOTZ, A. 2000. Migration after Apartheid: deracialising South African foreign policy. Third World Quarterly, 21(5):831-847.

KOHLI, R. 2006. The comfort of strangers: social work practice with unaccompanied asylum-seeking children and young people in the UK. Child and Family Social Work, 11(1):1-10.

KOK, P., GELDERBLOM, D., OUCHO, J. \& VAN ZYL, J. 2006. Migration in South and Southern Africa, dynamics and determinants. Cape Town: Human Sciences Research Council Press.

LESSER L., FERNÁNDEZ-ALFARO, B., COWIE, L. \& BRUNIN, X. 2006. IntraCaribbean migration and the Conflict Nexus. [Online] Available: http://www. unhcr.org/cgi-bin/texis/vtx/search?page=search\&query=the+attitudes\%2C+prejudices + and+behaviour+that+reject $\% 2 \mathrm{C}+$ exclude+and+often+vilify+persons $\% 2 \mathrm{C}+$ based + on $+\mathrm{t}$ he+perception+that+they+are+outsiders+or+foreigners+to+the+community $\% 2 \mathrm{C}+$ societ $\mathrm{y}+$ or+national+identity $\& \mathrm{x}=6 \& \mathrm{y}=21$ [Accessed: 05/11/2012].

MAKIENA, X. 2010. Zimbabwe's exodus crisis, migration, survival. Ottawa: International Development Research Centre.

McDONALD, D.A., ZINYAMA, L., GAY, J., DE VLETTER, F. \& MATTES, R. 2000. Guess who's coming to dinner: migration from Lesotho, Mozambique and Zimbabwe to South Africa. International Migration Review, 34(3):813-841.

MTHATHI, S. 2011. South Africa: Open New Johannesburg Refugee Center. [Online] Available: http://www.hrw.org/news/2011/06/02/south-africa-open-new-johannesburg-refugee-center. [Accessed: 05/10/2012].

NORD, A. \& ASSUBUJI, P. 2010. Editorial. Cape Town: Heinrich Boell Stiftung Southern Africa.

PARKER, F. 2012. Xenophobia rears its head as 'war' declared in Mayfair. Mail and Guardian, 3 September. 
PITTAWAY, E., MULI, C. \& SHTEIR, S. 2009. "I have a voice - hear me!" Findings of an Australian Study examining the resettlement and integration experience of refugees and migrants from the horn of Africa in Australia. Refuge, 26(2):133-146.

POLZER, T. 2008. Silence and fragmentation: South African responses to Zimbabwean migration. [Online] Available: http://idrc.ca/rpe/ev-158072-201-1-DO TOPIC.html [Accessed: 10/10/2012].

POLZER, T. n.d. Population movements in and to South Africa. Johannesburg: University of Witwatersrand.

POSEL, D. 2003. Have migration patterns in Post-Apartheid South Africa changed? Johannesburg, South Africa: s.n.

REPUBLIC OF SOUTH AFRICA. 2007. Immigration Amendment Act, No 3. Pretoria: Government Printers.

RUGUNANAN, P. \& SMIT, R. 2012. Seeking refuge in South Africa: challenges facing a group of Congolese and Burundian refugees. Development Southern Africa, 28(5):705718.

SAMUEL, E. 2009. Acculturative stress: South Asian immigrant women's experiences in Canada's Atlantic Provinces. Journal of Immigrant \& Refugee Studies, 7(1):16-34.

SCHOCKAERT, L. 2010. An MSF perspective: assisting those hidden from view [Interview] (March 2010).

SIGSWORTH, R., NGWANE, C. \& PINO, A. 2008. The gendered nature of xenophobia in South Africa. Johannesburg: The Centre for the Study of Violence and Reconciliation (CSVR).

VALJI, N. 2003. Creating the nation: the rise of violent xenophobia in the new South Africa. York: York University.

VERRYN, R.P. 2009. Personal communication [Interview] (19 April 2009).

WEINE, S.M., HOFFMAN, Y., WARE, N., TUGENBERG, T., HAKIZIMANA, L., DAHNWEIGH, G., CURRIE, M., \& WAGNER, M. 2011. Secondary migration and relocation among African refugee families in the United States. Family Process, 50(1) :27-46.

Prof Wim Roestenburg, Department of Social Work, University of South Africa, Pretoria, South Africa. 